\title{
ĐặC ĐIỂM BIẾN CHỬNG HÔ HẤP CỦA BỆNH LÝ BƯớU GIÁP CHÈN ÉP KHÍ QUẢN
}

\section{Nguyễn Hoài Nam*, Trần Lê Bảo Châu*, Trần Minh Bảo Luân*, Huỳnh Quang Khánh*}

\section{TÓM TÁ̀T}

Đặt vấn đề: Một số nghiên cứu chỉ ra rằng $33 \%$ bệnh nhân bướu giáp có triệu chứng chèn ép. Bệnh lý bướu giáp chèn ép gây hẹp đường thở là một trong những chỉ định ngoại khoa của bệnh lý bướu giáp. Triệu chứng chèn ép không chỉ ảnh hưởng về lâm sàng đối vối bệnh nhân mà còn là một vấn đề đối với gây mê và hồi sức chu phẫu.

Phương pháp nghiên cứu: Hồi cứu mô tả cắt ngang. Chúng tôi thu nhận được 52 bệnh nhân được chẩn đoán bướu giáp chèn ép khí quản đến khám và có điều trị phẫu thuật tại khoa Ngoại Lồng Ngực bệnh viện Chợ Rẫy từ tháng 01/2015 đến hết tháng $03 / 2019$. Tiêu chuẩn loại trừ: $\mathrm{BN}$ có u phối hợp vùng cổ gây chèn ép khí quản, Ung thư tuyến giáp có hình ảnh xâm lấn khí quản trên CT scan.

Kết quả nghiên cứu: Tuổi trung bình nhóm nghiên cứu $62.15 \pm 12.71$, tỉ lệ nam/nữ xấp xỉ 1:4. Tại thời điểm nhập viện, có 3 trường hợp đang điều trị viêm phổi, 4 trường hợp đang đặt $\mathrm{NKQ}$ và 1 trường hợp đã được mở khí quản trong tổng số 52 ca, như vậy có $15.38 \%$ bệnh nhân có vấn đề hô hấp tại thời điểm nhập viện. Đặc điểm của bướu giáp chèn ép khí quản thường là bướu có kích thước lớn, phân độ từ độ II trở lên, trên 80\% có thòng trung thất. Đường kính khí quản nhỏ nhất đo được là $3 \mathrm{~mm}$. Đường kính khí quản nhỏ nhất trung bình tính ra là $8.15 \pm 3.40$. Phân nhóm khí quản hẹp đa số bệnh nhân thuộc nhóm kích thước từ $5-10 \mathrm{~mm}$, chiếm $73.1 \%$ Tỉ lệ bệnh nhân đặt nội khí quản khó là $61.5 \%$. Kết quả tốt của phẫu thuật là $86.54 \%$, tỉ lệ biến chứng sau phẫu thuật là $13.46 \%$ bao gồm các biến chứng suy hô hấp, tê tay, liệt dây thanh và tụ dịch trung thất, ngoài ra không có trường hợp nào tử vong. Tỉ lệ suy hô hấp sau mổ là 3.8\%. Tỉ lệ đặt lại nội khí quản là $1.9 \%$. Ghi nhận chỉ có 2 trường hợp mềm sụn khí quản được đánh giá trong mổ và cả hai trường hợp đều được xử lý bằng cách khâu treo khí quản.

Kết luận: Phẫu thuật điều trị bệnh lý bướu giáp chèn ép khí quản cho kết quả sớm tốt. Phẫu thuật ở thời điểm sớm giúp bệnh nhân nhanh chóng hồi phục hô hấp nhanh chóng sau phẫu thuật. Trong phẫu thuật, cần chú ý các vấn đề: gây mê đặt NKQ, nhuyễn sụn khí quản và liệt dây thanh sau mổ.

Key word: buớu giáp chèn ép khí quản, nhuyễn sụn khi quản, hẹp khí quản

\section{EVALUATED RESPIRATORY PROBLEM IN GOITER COMPRESSING TRACHEA SUMMARY}

Background: Some studies indicate that $33 \%$ of goiter patients have symptoms of compression. A pinched thyroid disease is one of the surgical designations of goiter. Compression symptoms are not only clinically relevant for the patient, but are also a problem for general anesthesia and resuscitation.

Methods: Retrospective cross-sectional

* Bệnh viện Chợ Rẫy

Nguời chịu trách nhiệm khoa học: Nguyễn Hoài Nam

Ngày nhận bài: 13/01/2021 - Ngày cho phép đăng: 02/04/2021 
description. We recruited 52 patients diagnosed with tracheotropic goiter to undergo medical examination and surgery at the Department of Thoracic Surgery at Cho Ray Hospital from January 2015 to the end of March 2019. Exclusion criteria: Patients with cervical tumor combined to cause compression of the trachea, Thyroid cancer with image of invasive trachea on CT scan.

Results: The average age of the study group was $62.15 \pm 12.71$, the male / female ratio was approximately $1: 4$. At the time of admission, 3 cases were being treated for pneumonia, 4 were undergoing intubations and 1 had a tracheotomy in a total of 52 cases, so $15.38 \%$ of patients had respiratory problems in time of admission. The smallest diameter of trachea is $3 \mathrm{~mm}$. The mean minimum trachea diameter is calculated to be $8.15 \pm 3.40$. Narrow tracheal grouping, the majority of patients were from 5 to $10 \mathrm{~mm}$ size, accounting for $73.1 \%$. The proportion of patients with difficult intubation was $61.5 \%$. The good result of surgery is $86.54 \%$, the rate of complications after surgery is $13.46 \%$ including complications of respiratory failure, hand numbness, vocal paralysis and mediastinal fluid, besides there are no deaths. The rate of respiratory failure after surgery is $3.8 \%$. The rate of re-intubation was $1.9 \%$. Only 2 cases of trachealmalasia were detected in surgery and both cases were treated by tracheostomy.

Conclusion: Surgery to treat tracheal goiter for good early results. Surgery in the early stage helps the patients recovered respiration quickly after surgery. During surgery, attention should be paid to the following issues: anesthenesis, trachealmalasia and vocal cord paralysis.

Key word: goitre compressing trachea, trachealmalasia, tracheal stenosis

\section{ĐẶ V VẤN ĐỀ}

Bệnh lý bướu giáp chèn ép gây hẹp đường thở là một trong những chỉ định ngoại khoa của bệnh lý bướu giáp. Theo một nghiên cứu của $\mathrm{J}$. M. Findlay, trong số các bệnh nhân được phẫu thuật tuyến giáp, có khoảng $19 \%$ bệnh nhân có chèn ép khí quản với đường kính lòng khí quản từ 2 - 15 mm, trong đó 6\% bệnh nhân có hẹp nặng khí quản với đường kính lòng khí quản $<5 \mathrm{~mm}$ [1]. Triệu chứng chèn ép không chỉ ảnh hưởng về lâm sàng đối vối bệnh nhân mà còn là một vấn đề đối với gây mê và hồi sức chu phẫu. Một số nghiên cứu chỉ ra rằng $33 \%$ bệnh nhân bướu giáp có triệu chứng chèn ép [2]. Nghiên cứu của $\mathrm{A}$. Alfonso cho thấy, $1 / 3$ bệnh nhân có bằng chứng hình ảnh học đẩy lệch khí quản không có triệu chứng chèn ép [3]. Mặc dù vậy, về lâu dài việc đẩy lệch hay làm hẹp lòng khí quản sẽ gây ảnh hưởng đến chức năng hô hấp của bệnh nhân. Do đó, chỉ định ngoại khoa điều trị bệnh lý bướu giáp chèn ép khí quản cần được cân nhắc. Chỉ định phẫu thuật đối với bệnh lý này có liên quan chặt chẽ đến việc đặt nội khí quản trong gây mê và vấn đề hô hấp của bệnh nhân sau phẫu thuật. Ngoài ra trong một số trường hợp, bệnh nhân có triệu chứng khó thở do chèn ép có chỉ định đặt nội khí quản hoặc mở khí quản cấp cứu, bướu giáp lớn là một khó khăn khi phẫu thuật cần phải có biện pháp can thiệp hiệu quả nhằm giải quyết tình trạng cấp cứu của bệnh nhân. Chính vì lý do trên, chúng tôi tiến hành nghiên cứu về đặc điểm hô hấp trước và sau mổ bướu giáp chèn ép khí quản.

\section{PHƯƠNG PHÁP NGHIÊN CÚU}

Chúng tôi thực hiện nghiên cứu mô tả hàng loạt ca 52 bệnh nhân được chẩn đoán bướu giáp chèn ép khí quản đến khám và có điều trị phẫu thuật tại khoa Ngoại Lồng Ngực bệnh viện Chợ 
Rẫy từ tháng 01/2015 đến hết tháng 03/2019. Chúng tôi loại trừ bệnh nhân ung thư tuyến giáp có hình ảnh xâm lấn khí quản trên $\mathrm{CT}$ scan. Chẩn đoán hẹp khí quản dựa trên hình ảnh $\mathrm{CT}$ scan: đường kính cắt ngang đoạn khí quản nhỏ nhất $<15 \mathrm{~mm}$ [30].

Phân loại mức độ hẹp khí phế quản [4]:

- Độ 0: Không hẹp.

- Độ I: Hẹp từ 1 đến $25 \%$ khẩu kính khí phế quản.

- Độ II: Hẹp từ 26 đến 50\% khẩu kính khí phế quản.

- Độ III: Hẹp từ 51 đến 75\% khẩu kính khí phế quản.

- Độ IV: Hẹp từ 76 đến 90\% khẩu kính khí phế quản.

- Độ V: Hẹp từ trên 90\% đến toàn bộ khẩu kính khí phế quản

BN trước gây mê được đánh giá các chỉ số ASA và đánh giá phân độ Mallampati tiên lượng đặt nội khí quản khó. BN được đánh giá đặt NKQ khó do bác sĩ gây mê có kinh nghiệm từ 2 năm lâm sàng trở lên và đánh giá là đặt NKQ khó. Nhuyễn sụn khí quản được chẩn đoán trong lúc mổ. Phẫu thuật viên là người đánh giá tình trạng khí quản có mềm hơn so với đoạn khí quản bình thường không bị chèn ép. Xử trí mở khí quản hoặc khâu treo khí quản được quyết định bởi phẫu thuật viên trong mổ. BN được mở khí quản hậu phẫu khi liệt khép dây thanh do tổn thương thần kinh quặt ngược hoặc thở máy lâu dài do tình trạng viêm phổi.

\section{Kết quả phẫu thuật:}

Kết quả tốt: Thực hiện thành công phẫu thuật và không có biến chưng.
Kết quả trung bình: Thực hiện thành công phẫu thuật nhung có các biến chứng: hạ canxi máu, khàn tiếng, tu dịch vết mổ, nhiễm trùng vết mổ.

Kết quả xấu: Không cắt được buớu hoạcc cắt được bướu nhung có các biến chưng nặng: liệt dây thanh 2 bên phải mở khí quản, suy hô hấp, chảy máu sau mổ phải mổ lại, tổn thuoong cấu trúc xung quanh nhu thủng thục quản, thủng khí quản, ống ngụcc... Tử vong trong hoặc sau mổ

\section{KẾT QUẢ}

Tuổi trung bình nhóm nghiên cứu $62.15 \pm$ 12.71, tỉ lệ nam/nữ xấp xỉ 1:4. Tại thời điểm nhập viện, có 3 trường hợp đang điều trị viêm phổi, 4 trường hợp đang đặt $\mathrm{NKQ}$ và 1 trường hợp đã được mở khí quản trong tổng số $52 \mathrm{ca}$, như vậy có $15.38 \%$ bệnh nhân có vấn đề hô hấp tại thời điểm nhập viện. Đặc điểm của bướu giáp chèn ép khí quản thường là bướu có kích thước lớn, phân độ từ độ II trở lên, trên $80 \%$ có thòng trung thất. Về lâm sàng, tuổi mắc bệnh cao hơn so với bệnh lý bướu giáp thường gặp, thời gian mắc bệnh trung bình là 7.10 năm

Đường kính khí quản nhỏ nhất đo được là 3 $\mathrm{mm}$. Đường kính khí quản nhỏ nhất trung bình tính ra là $8.15 \pm 3.40$. Phân nhóm khí quản hẹp đa số bệnh nhân thuộc nhóm kích thước từ $5-10$ mm, chiếm 73.1\%. Mức độ hẹp trung bình của khí quản là 49.47\%. Vị trí hẹp chủ yếu ở đoạn cổ, tỷ lệ $46.2 \%$ trong dân số nghiên cứu, tỷ lệ hẹp đoạn ngực là $25 \%$ trường hợp và tỷ lệ hẹp cả đoạn cổ và đoạn ngực là $28.8 \%$

Tỉ lệ bệnh nhân đặt nội khí quản khó là $61.5 \%$. Ghi nhận $90 \%$ đường mổ là đường mở cổ. Có 1 trường hợp mở xương ức từ đầu do chẩn đoán trước mổ là u trung thất. Ngoài ra 4 trường 
hợp mở cổ kết hợp mở xương ức chiếm 7.7\%, chủ yếu do bướu giáp to thòng trung thất không thể lấy hết qua đường mở cổ. Phương pháp phẫu thuật chiếm đa số là cắt gần trọn tuyến giáp với tỷ lệ $46.2 \%$, có $35 \%$ trường hợp được phẫu thuật cắt trọn một thùy tuyến giáp gây chèn ép. Dưới $20 \%$ bệnh nhân phải cắt toàn bộ hai thùy tuyến giáp. Thời gian phẫu thuật trung bình là $2.10 \pm 0.53$ giờ. Thời gian rút nội khí quản trung bình là $18.423 \pm 47.34$ giờ. Thời gian hậu phẫu trung bình là $5.04 \pm 3.372$ ngày.

Kết quả tốt của phẫu thuật là $86.54 \%$, tỉ lệ biến chứng sau phẫu thuật là $13.46 \%$ bao gồm các biến chứng suy hô hấp, tê tay, liệt dây thanh và tụ dịch trung thất, ngoài ra không có trường hợp nào tử vong. Tỉ lệ suy hô hấp sau mổ là $3.8 \%$. Tỉ lệ đặt lại nội khí quản là 1.9\%.

Ghi nhận chỉ có 2 trường hợp mềm sụn khí quản được đánh giá trong mổ và cả hai trường hợp đều được xử lý bằng cách khâu treo khí quản.

\section{Bảng 1: Đặc điểm lâm sàng và CT scan nhóm nghiên cứu}

\begin{tabular}{|c|c|c|}
\hline & Số BN $(n=52)$ & Tỉ lệ \% \\
\hline \multicolumn{3}{|l|}{ Giới tính } \\
\hline Nam & 4 & 7 \\
\hline Nữ & 48 & 93 \\
\hline Tuổi trung bình (năm) & \multicolumn{2}{|c|}{$62.15 \pm 12.71$} \\
\hline Thời gian mắc bệnh bướu giáp & \multicolumn{2}{|c|}{$7.10 \pm 6.76$ năm } \\
\hline \multicolumn{3}{|l|}{ Triệu chứng hô hấp trước mổ } \\
\hline Khó thở & 22 & 42.3 \\
\hline Viêm phổi đang điều trị & 3 & 5.8 \\
\hline Đang đặt NKQ & 4 & 7.7 \\
\hline Mở khí quản & 1 & 1.9 \\
\hline \multicolumn{3}{|l|}{ Phân độ bướu giáp } \\
\hline Độ 1 & 0 & 0 \\
\hline Độ 2 & & 11.5 \\
\hline Độ 3 & & 53.8 \\
\hline Độ 4 & & 34.6 \\
\hline \multicolumn{3}{|l|}{ Chức năng hô hấp (n=17) } \\
\hline Bình thường & 10 & 58.82 \\
\hline Tắc nghẽn nhẹ & 2 & 11.76 \\
\hline Tắc nghẽn trung bình & 3 & 17.65 \\
\hline Tắc nghẽn nặng & 2 & 11.7 \\
\hline Đặt NKQ khó & & 61.5 \\
\hline Bướu giáp thòng trung thất & & 87.5 \\
\hline \multicolumn{3}{|l|}{ Phân nhóm ĐK hẹp khí quản } \\
\hline$<5 \mathrm{~mm}$ & & 15.4 \\
\hline $5-10 \mathrm{~mm}$ & & 73.1 \\
\hline$>10 \mathrm{~mm}$ & & 11.5 \\
\hline Đường kính KQ hẹp trung bình (mm) & $8.15 \pm 3.40$ & \\
\hline
\end{tabular}




\section{Bảng 2: Đặc điểm phẫu thuật và hậu phẫu}

\begin{tabular}{ccc}
\hline & Số BN (n=52) & Tỉ lệ \\
\hline Đường mổ & & \\
& Mở cổ & 90.4 \\
Mở cổ + mở xương ức & & 9.6 \\
Phương pháp phẫu thuật & 10 & 19 \\
Cắt toàn bô TG & 18 & 35 \\
Cắt 1 thuỳ TG & 24 & 46 \\
Cắt gần trọn TG & & \\
Thở máy & 6 & 11.5 \\
Suy hô hấp & 2 & 3.8 \\
Đặt lại NKQ & 1 & 1.9 \\
Suy hô hấp sau mồ & & 3.8 \\
Nhuyến chứng sụn khí quản & 2 & 3.8 \\
Liệt khép dây thanh & 2 & 7.2 \\
Mở khí quản sau mổ & 4 & 3.8 \\
Tê tay & 2 & 1.9 \\
Tụ dịch trung thất & 1 & \\
\hline
\end{tabular}

Bảng 3: Các yếu tố liên quan thở máy sau mổ

\begin{tabular}{|c|c|c|}
\hline ĐẶT NKQ TRƯỚC MỔ & Thò̀i gian rút NKQ & Giá trị p \\
\hline CÓ $(n=4)$ & $10.9375 \pm 10.795$ & \multirow{2}{*}{0.0001} \\
\hline KHÔNG $(\mathrm{n}=48)$ & $108.25 \pm 156.89$ & \\
\hline \multicolumn{2}{|l|}{ VIÊM PHỔI } & \multirow{3}{*}{0.845} \\
\hline CÓ (n = 3) & $18.7449 \pm 48.7247$ & \\
\hline KHÔNG (n = 49) & $13.1667 \pm 11.094$ & \\
\hline \multicolumn{2}{|l|}{ SUY HÔ HÂPP TRƯỚC MỔ } & \multirow{3}{*}{0.002} \\
\hline CÓ $(n=6)$ & $74.083 \pm 132.607$ & \\
\hline KHÔNG $(\mathrm{n}=49)$ & $11.163 \pm 10.91$ & \\
\hline \multicolumn{2}{|l|}{ Mức độ hẹp khí quản } & \\
\hline$\geq 50 \%(\mathrm{n}=29)$ & $20.0517 \pm 61.4673$ & \multirow{2}{*}{0.784} \\
\hline$<50 \%(\mathrm{n}=23)$ & $16.3696 \pm 19.545$ & \\
\hline
\end{tabular}




\section{BÀN LUẬN}

Bướu giáp đa nhân lành tính sẽ có tình trạng lớn lên và dẫn đến chèn ép khí quản, các báo cáo cho thấy $76,6 \%$ BN có bướu giáp đa nhân lành tính sẽ phát triển và biểu hiện thành hội chứng chèp ép các cơ quan xung quanh, 2-3\% bướu giáp đa nhân sẽ phát triển thành ung thư sau thời gian trung bình là 4.5 năm [5]. Nghiên cứu chúng tôi ghi nhận thời gian biết bệnh bướu giáp trung bình của bệnh là $7.10 \pm 6.76$ năm, thời gian mắc bệnh lâu nhất là 40 năm. Bùi Viết Hoàng [6] ghi nhận thời gian phát triển bướu giáp là 12,1 năm, $52 \%$ bệnh nhân có thời gian phát triển từ $10-20$ năm và $11,5 \%$ có thời gian phát triển bướu $>20$ năm. Binu Sajid [7] cho thấy thời gian mắc bệnh trung bình của 50 bệnh nhân bướu giáp chèn ép khí quản là 10.81 năm, và thời gian mắc bệnh lâu nhất là 30 năm. Như vậy, bướu giáp chèn ép khí quản có thời gian mắc bệnh lâu, bướu lớn dần lên gây các triệu chứng chèn ép khiến bệnh nhân nhập viện điều trị.

Triệu chứng chèn ép đường thở do bướu giáp lớn chèn ép biểu hiện với nhiều mức độ: ho khan, thở rít, thở co kéo, suy hô hấp cấp hoặc đôi khi là biểu hiện viêm phổi tái phát nhiều lần. Trong nghiên cứu chúng tôi ghi nhận được bệnh nhân có triệu chứng khó thở chiếm $65.4 \%$, thở rít $3.8 \%$, thở co kéo $7.7 \%$. Ngoài ra, có $5.8 \%$ bệnh nhân đang điều trị viêm phổi, $7.7 \%$ bệnh nhân suy hô hấp được đặt khí quản lúc nhập viện. Tác giả Micheal T Stang [8] nghiên cứu $188 \mathrm{BN}$ có triệu chứng khó thở tư thế trong $1081 \mathrm{BN}$ bướu giáp được phẫu thuật cho thấy rằng $93.5 \% \mathrm{BN}$ khó thở tư thế có chèn ép khí quản được xác định thông qua chẩn đoán hình ảnh và sau phẫu thuật cắt tuyến giáp $82,4 \%$ sẽ mất triệu chứng khó thở tư thế. Tác giả nhận định triệu chứng khó thở tư thế là một dấu hiệu quan trọng của tình trạng bướu giáp chèn ép khí quản và là một chỉ định phẫu thuật cắt bướu giáp làm giảm sự chèn ép khí quản.

Chúng tôi ghi nhận trong nghiên cứu đường kính khí quản từ 5-10 mm chiếm tỉ lệ cao nhất là $73.1 \%$, đường kính khí quản hẹp khít $<5 \mathrm{~mm}$ là $15.4 \%$. Binu Sajid [7]báo cáo trên $50 \mathrm{BN}$ cho thấy tỉ lệ khí quản hẹp từ $5-10 \mathrm{~mm}$ là $44 \%$ và đường kính khí quản hẹp khít $<5 \mathrm{~mm}$ là $8 \%$. Tác giả còn nhận thấy các $\mathrm{BN}$ hẹp khít khí quản $<5 \mathrm{~mm}$ cần sử dụng nội soi khí quản dẫn đường trong lúc gây mê đặt nội khí quản. Dempsey [9] ghi nhận có sự tương quan giữa triệu chứng khò khè với đường kính của khí quản, tác giả ghi nhận $23 \% \mathrm{BN}$ có triệu chứng khò khè trước mổ, trong đó $66,7 \% \mathrm{BN}$ có đường kính khí quản hẹp khít < $5 \mathrm{~mm}$. Sorensen [10] ghi nhận kích thước khí quản trên $65 \mathrm{BN}$ bướu giáp chèn ép khí quản cho thấy diện tích khí quản trung bình là $1.5 \mathrm{~cm}^{2}$, nhóm $\mathrm{BN}$ có bướu giáp chèn ép vùng cổ có diện tích khí quản hẹp là $1.6 \mathrm{~cm}^{2}$ và nhóm $\mathrm{BN}$ có bướu giáp thòng chèn ép có diện tích khí quản là $1.1 \mathrm{~cm}^{2}$.

Nghiên cứu chúng tôi ghi nhận có $61.5 \%$ trường hợp đặt nội khí quản khó trong lúc gây mê. Findlay [1] ghi nhận có 7/62 bệnh nhân có kích thước khí quản $<5 \mathrm{~mm}$ cần phải đặt nội khí quản có lò xo khi còn tỉnh vì bệnh nhân sẽ ngưng thở khi nằm ngửa. Tác giả cho thấy ống nội khí quản số 7 thường được sử dụng nhất là 33/62 bệnh nhân, có $7 / 62$ bệnh nhân cần sử dụng ống nội khí quản số 6 . Binu Sajid [7] cho thấy tất cả 50 bệnh nhân bướu giáp chèn ép khí quản đều có tình trạng đặt nội khí quản khó, kích thước của ống nội khí quản từ 6 đến $8.5 \mathrm{~mm}$ và có $24 \% \mathrm{BN}$ phải đặt nội khí quản nhỏ hơn so với kích thước cần thiết. 
Tác giả Trần Thị Cẩm Nhung [11] báo cáo 120 BN gây mê đặt nội khí quản cho phẫu thuật bướu giáp nhận thấy $26,6 \% \mathrm{BN}$ tiên lượng đặt nội khí quản khó, trong khi thật sự khó chiếm 10.8\%. Tác giả còn cho thấy những yếu tố tiên lượng đặt NKQ khó trong 13 trường hợp đặt nội khí quản khó: $30,8 \%$ có khoảng cách hai hàm răng $<4 \mathrm{~cm}$ đặt nội khí quản khó, 38,5\% khoảng cách cằm giáp < $6 \mathrm{~cm}$ đặt nội khí quản khó, 30,8\% Mallampati độ III đặt nội khí quản khó, 38,5\% Cormack - Lehane độ III nội khí quản khó, 7,7\% bướu giáp thòng trung thất có đẩy lệch khí quản, đặt nội khí quản khó.

\section{KẾT LUẬN}

Các yếu tố hô hấp lâm sàng trước mổ có ảnh hưởng quan trọng đến kết quả phẫu thuật và gây mê hồi sức gồm có: tuổi trung bình mắc bệnh cao hơn so với bệnh lý bướu giáp khác, bướu giáp phát triển trong thời gian dài dẫn đến suy hô hấp, kích thước đường kính khí quản nhỏ nhất $<5 \mathrm{~mm}$, biến chứng hô hấp trước mổ. Trong những trường hợp đó, việc hồi phục hô hấp sau mổ khó khăn hơn so với những bệnh nhân khác. Do đó, có thể thấy biến chứng hô hấp là một trong những hậu quả nặng nề của bệnh lý bướu giáp chèn ép khí quản, nhất là đối với những trướng hợp bệnh diễn tiến lâu ngày.

Phẫu thuật ở thời điểm sớm khi phát hiện bệnh là một phương pháp điều trị hiệu quả. Phẫu thuật tại thời điểm bệnh nhân chưa có biến chứng hô hấp còn giúp bệnh nhân phục hồi nhanh chóng sau mổ, giảm nguy cơ suy hô hấp khó hồi phục.

\section{TÀI LIỆU THAM KHẢO}

1. Findlay, J.M., et al., Postthyroidectomy tracheomalacia: minimal risk despite significant tracheal compression. $\mathrm{Br} \mathrm{J}$
Anaesth, 2011. 106(6): p. 903-6.

2. Banks, C.A., et al., Thyroid disease and compressive symptoms. Laryngoscope, 2012. 122(1): p. 13-6.

3. Alfonso, A., et al., Tracheal or esophageal compression due to benign thyroid disease. Am J Surg, 1981. 142(3): p. 350-4.

4. Freitag, L., et al., A proposed classification system of central airway stenosis. Eur Respir J, 2007. 30(1): p. 7-12.

5. Fujita, T., The Natural History of Multinodular Goiter. Journal of the American College of Surgeons, 2015. 221(4): p. 893-894.

6. Hoàng, B.V., Đánh giá kết quả điều trị Ngoại khoa bướu giáp lành tính thòng vào trung thất. 2016, Đại học Y dược TP. HCM. p. 6.

7. Sajid, B. and K. Rekha, Airway management in patients with tracheal compression undergoing thyroidectomy: A retrospective analysis. Anesthesia: Essays and Researches, 2017. 11(1): p. 110-116.

8. Stang, M.T., et al., Positional Dyspnea and Tracheal Compression as Indications for Goiter ResectionPD and TC as Indications for Goiter Resection. JAMA Surgery, 2012. 147(7): p. 621-626.

9. Dempsey, G.A., et al., Anaesthesia for massive retrosternal thyroidectomy in a tertiary referral centre. Br J Anaesth, 2013. 111(4): p. 594-9.

10. Sorensen, J.R., et al., Thyroidectomy Improves Tracheal Anatomy and Airflow in Patients with Nodular Goiter: A Prospective Cohort Study. Eur Thyroid J, 2017. 6(6): p. 307-314.

11. Chừng, T.t.C.N.L.V.Q.N.V., Nghiên cứu những yếu tố tiên lượng khó đặt NKQ trong phẫu thuật bệnh lý tuyến giáp. Tạp chí Y học TP. Hồ Chí Minh, 2011. 15: p. 75-80. 